specific organism, and am now engaged in making cultures from the exudation. In the meantime I have ventured to trespass on your valuable space to ask for aid in the explanation of what seems to be a most unusual and nnexpected occurrence, and to ask if similar outbreaks are occurring or have occurred elsewhere. I may add that the cases have been seen by several other medical men, all of whom concur in the opinion that it is neither impetigo contagiosa nor any other disease, but true vesicular eczema.

$$
\text { I am, Sirs, yours truly, }
$$

Thos. Savilu, M.D.,

July 27th, 1891. Medical Superintendent, Paddington Infirmary, W.

\section{"JOHN HUNTER'S HEIGHT."}

To the Editors of THE LANCET.

SIRs,-Many of your readers must have been somewhat surprised to learn from Mr. Bailey's letter in your last issue that John Hunter was only $5 \mathrm{ft}$. 2 in. in height. It is, however, made very evident, I think, by the famous portrait by Sir Joshua Reynolds that Hunter was a small man. Mr. Bailey has since told me that he carefully examined the picture in the light of his discovery, and that to himwhether it was because he saw what he wanted to see he
could not say-the portrait seemed that of a man under the average size. On hearing this, I had a fresh look at the picture, and the immediate impression made upon my own mind was certainly the same. I should say that it represents not merely a short, but a small man, for a man may be short without being little. Judging from it, I imagine Hunter to have been small-boned and slender, weighing about 9 st., or, if anything, less, and with a head proportionate in size to the body, and therefore below the average. The portrait of his brother William, hanging in the same room, appears also to be that of a small man.

July 27 th, 1891. I am, Sirs, yours faithfully, HARRY CAMPBELT.

\section{THE DANGER OF CHLOROFORM AND THE SAFETY OF ETHER AS AN ANASTHETIC.} To the Editors of THE LANCET.

SIRs,-No operating surgeon can - read the medical journals' record week after week of "Another Death from Chloroform" without thinking of the possibility of such a catastrophe occurring in his own practice and how it may be averted. I have frequently, in THE LANCET and elsewhere, brought before operating surgeons the responsibility incurred by subjecting a human being to the influence of chloroform as being the most dangerous form of anæsthetic. But since the report of the Hyderabad Commission was published deaths from chloroform seem to be largely on the increase. At the Manchester Royal Infirmary, for example, since the beginning of the present year there were two deaths reported to have taken place during the administration of chloroform. Seeing that, apart from the climatic effects, the experiments of the Hyderabad Commission were mostly carried out on Indian dogs and monkeys, it is surprising that scientific men should rely on results so obtained, ignoring statistics with regard to human beings, which attest beyond all manner of doubt the danger of chloroform and the comparative safety of ether. I for one do not consider the results of the
Hyderabad Commission conclusive or satisfactory, for I have too frequently witnessed at the operating table most painful incidents. I have seen patients under chloroform suddenly cease to breathe. The operation stopped, and all the while awful suspense takes possession both of the operator and the anæsthetist. Last week I witnessed in Dublin a fatal case from the administration of chloroform. The patient was a finelooking robust man, aged about fifty, suffering from cancer of the tongue. The surgeon who was about to remove the diseased part directed the house surgeon to administer chloroform, who carefully examined the patient's heart before the operation, and found it normal. On a previous occasion the man had been given ether to produce anæsthesia, but it was reported that he did not take ether well, though he was put under its influence all the same. Hence chloroform was administered on this occasion, in the most careful manner, with Skinner's apparatus. The man gave buttwo or three inspirations, when he died as suddenly as if shot through the heart. There was no sign of impeded breathing, no pallor of cheek -in fact, no warning whatever. Never shall I forget the consternation of those concerned; and no wonder, for here was a man in the plenitude of life and apparent vigour, cheerful in spirits, changed, with the appalling suddenness of a ljghtning flash, into a corpse. All means of resuscitation were promptly resorted to, but in vain; the man was dead. I consider it nothing short of culpable recklessness, with so many warnings, for any surgeon to persist in the use of chloroform in preference to ether on the score of convenience. No doubt death may be produced by any anæsthetic, if pushed too far or admini. stered by an inexperienced or careless person ; and with such persons it often happens that an operator has to warn the administrator to devote his entire attention to the anasthesia and not mind the operation. In certain small and rapid operations I think administrators frequently produce a greater degree of anæsthesia than necessary, and do not estimate the exact amount of anæsthesia requisite for the painless performance of any given operation. As the result of my own observation chloroform seems to act as a direct poison on some persons, and kills, when it does kill, as suddenly as a pistol bullet would whose billet was the heart or brain. It gives no warning sign or indication till fatal symptoms are apparent and the patient is either actually dead or beyond any means of resuscitation.

Of ether my experience is different. It always gives warning, and the untoward effect may be almost instantly removed. Acting as it does directly on the respiratory functions, methods of resuscitation, as regards artificial respiration, can be immediately applied, and are, as a rule, nearly always successful. So long as I have the strong convictions which I entertain, based upon many years of practice, regarding the choice of an anæsthetic, I will raise my voice against the wanton administration of chloroform in preference to ether, which has been proved by undeniable statistics to be the safest anæsthetic known.

I am, Sirs, yours faithfully,

L. HEPENSTAL-ORMSBY, M.D., F.R.C.S., Surgeon to the Meath Hospital and County Dublin Infirmary. Merrion-square West, Dublin, July 20th, 1891.

\section{THE DEATH UNDER CHLOROFORM AT BIRKENBEAD.}

To the Editors of THE LANCET.

Sirs, - I beg to forward you the particulars of the recent death under chloroform here.

J. Hon July 10th, suffering from an abscess of the lefo bursa patella and a fibrous tumour of the right. The abscess was opened, and on the 15th the patient was placed under chlo. roform for the purpose of removing the tumour. The patient struggled a good deal while going under, but otherwise took the anæesthetic well. After he was fairly under, and the operating surgeon had made a small incision over the tumour, the pupils were ooserved to suddenly dilate, and the breathing to become shallow. The anæsthetic was at once stopped. The tongue was drawn out, brandy injected, and artificial respiration kept up for over half an hour, but all of no avail. The quantity of chloroform given was two drachms and a half. Death occurred six minutes after the commencement of the anresthetic. No post-mortem examination.-I am, Sirs, yours truly,

Birkenhead, July, 1891.

W. R. MAIN.

\section{SUPPOSED DEATH FROM PTOMAINE POISON- ING AFTER EATING TINNED SALMON.}

\section{To the Editors of THE LANCET.}

SIRs,-As the following case may be of some interest, beg to forward you the same for publication. On June 28 th, $12 \mathrm{~A}$. M., I was summoned to a house in the neighbourhood with a message that a whole family had been poisoned. On my arrival I found six persons in bed - a lad aged twelve years (sincedeceased), three daughters, mother, and the cook. Upon. inquiring the cause, I ascertained that the six patients had all partaken for supper the previous night of tinned salmon, and after going to bed as usual were seized towards early morning with violent pains in the stomach, sickness, and diarrboa. I first saw the daughters, whom I found apparently in great pain, rolling about their beds, with a 